\title{
PRODUÇÃO DE CONÍDIOS DE METARHIZIUM ANISOPLIAE EM MEIO SÓLIDO À BASE DE RESÍDUOS AGROINDUSTRIAIS
}

\author{
L. Sene ${ }^{1}$ L.F.A. Alves ${ }^{1 *}$, M.F.P. Lobrigatte ${ }^{1 * *}$, D. Thomazoni ${ }^{2 * * *}$ \\ ${ }^{1}$ Universidade Estadual do Oeste do Paraná, Centro de Ciências Médicas e Farmacêuticas, Laboratório de \\ Tecnologia das Fermentações, Rua Universitária 2069, CEP 85819-110, Cascavel, PR, Brasil. E-mail: lsene@ \\ unioeste.br
}

\section{RESUMO}

As crescentes despesas com o custo do meio para o cultivo de Metarhizium anisopliae levantam a necessidade de averiguar a eficiência de alguns resíduos agroindustriais que, além de propriedades nutricionais importantes, possuem grande disponibilidade e baixo custo. Os experimentos foram conduzidos no Laboratório de Tecnologia das Fermentações, UNIOESTE, Campus de Cascavel, PR. Neste trabalho, foram avaliados como substratos arroz polido (meio padrão), arroz vermelho, arroz polido suplementado com melaço (2,5\%,5\% e 10\%), resíduo de cervejaria, resíduo de fecularia, arroz polido + resíduo de cervejaria (1:1) e arroz polido + resíduo de fecularia (1:1). Os experimentos foram realizados em triplicata, em frascos Erlernmeyer de $250 \mathrm{~mL}$ contendo $30 \mathrm{~g}$ do substrato (ou 15 g de cada, quando em mistura) e umidade de $70 \pm 10 \%$. Os frascos foram inoculados com $0,5 \mathrm{~mL}$ da suspensão de conídios $\left(1 \times 10^{8}\right.$ conídios $\left./ \mathrm{mL}\right)$ e incubados em BOD $\left(25 \pm 1^{\circ} \mathrm{C}\right.$, fotofase 12h, 7 dias). Dentre os meios testados, verificou-se uma elevada produção de conídios no meio composto por arroz + resíduo de cervejaria $\left(11,3 \times 10^{8}\right.$ conídios/g de substrato) e no arroz $(9,6 \times$ $10^{8}$ conídios $\left./ g\right)$. Os conídios produzidos no meio de arroz + resíduo de cervejaria apresentaram atividade inseticida frente a Spodoptera frugiperda semelhante a dos conídios produzidos no arroz. Este novo meio de cultivo poderá proporcionar uma redução de custo de aproximadamente 50\%, representando uma alternativa viável para a produção do fungo.

PALAVRAS-CHAVE:Metarhizium anisopliae, resíduos agroindustriais, fermentação em estado sólido.

\begin{abstract}
PRODUCTION OF CONIDIA OF METARHIZIUM ANISOPLIAE IN SOLID MEDIA BASED ON AGROINDUSTRIAL RESIDUES. Increasing costs of substrate for production of Metarizhium anisopliae raise the necessity of investigating the efficiency of some agro-industrial residues that, in addition to important nutritional properties, are widely available at low cost. The assays were conducted at the Fermentation Technology Laboratory, UNIOESTE, Cascavel, PR, Brazil. In this work, substrates such as polished rice (standard media), red rice, polished rice + sugar molasses $(2.5 \%, 5 \%$ and $10 \%)$, brewery residue, cassava residue, polished rice + brewery residue (1:1) and polished rice + cassava residue (1:1) were evaluated. The experiments were carried out in triplicate, in Erlernmeyer flasks of $250 \mathrm{~mL}$, containing $30 \mathrm{~g}$ of the substrate (or $15 \mathrm{~g}$ of each one, when as mixture) and moisture content of $70 \pm 10 \%$. The flasks were inoculated with $0.5 \mathrm{~mL}$ of conidia suspension $(1 \times 108$ conidia $/ \mathrm{mL})$ and then incubated in controlled temperature and light ( $25 \pm 1$ o C, 12 hours photophase, 7 days). High conidial production was verified in rice + brewery residue media $(11.30 \times 108$ conidia/g of substrate and in the polished rice $(9.59 \times 108$ conidia/g of substrate). The conidia produced in rice + brewery residue media showed an insecticidal activity against Spodoptera frugiperda similar to that attained with the conidia produced in rice. This new culture media may provide a reduction of approximately $50 \%$ in the production cost, thus presenting a viable alternative for the fungus production.
\end{abstract}

KEY WORDS: Metarhizium anisopliae, agro-industrial residues, solid-state fermentation.

${ }^{2}$ Universidade Estadual do Oeste do Paraná, Centro de Ciências Biológicas e da Saúde, Laboratório de Biotecnologia Agrícola, Cascavé, PR, Brasil.

*Bolsista de Produtividade em Pesquisa/CNPq.

**Bolsista de Iniciação Científica/Fundação Araucária.

***Bolsista de Iniciação Científica/CNPq. 


\section{INTRODUÇÃO}

Insetos em culturas agrícolas podem provocar perdas consideráveis na produção, acarretando prejuízo ao produtor, sendo que, tradicionalmente, o controle de pragas é realizado com agroquímicos. No entanto, devido aos custos e danos ambientais, medidas alternativas vêm sendo desenvolvidas, destacando-se o controle biológico de insetos a partir de formulações contendo entomopatógenos (biopesticidas). Recentemente, considerável progresso tem ocorrido com o desenvolvimento de agentes de controle biológico à base de fungos, havendo mais de 30 patentes de produtos biopesticidas já registrados ou em desenvolvimento em todo o mundo (KASSA, 2003).

Embora muitos micro-organismos sejam utilizados no controle de pragas da agricultura, estima-se que os fungos sejam mais frequentemente envolvidos nas doenças de insetos. Dentre os mais usados, salientam-se os gêneros Metarhizium, Beauveria, Lecanicillium, Nomuraea, Hirsutella, Entomophthor e Asckersonia (Melo; Azevedo, 1998). A espécie Metarhizium anisopliae encontra-se distribuída de forma ampla na natureza, sendo encontrada no solo, sobrevivendo por longos períodos. Acredita-se que este entomopatógeno ocorra naturalmente em mais de 300 espécies de insetos das diferentes ordens, incluindo pragas importantes como gafanhotos, Mahanarva posticata (cigarrinha-de-folhas da cana-deaçúcar) e Mahanarva fimbriolata (cigarrinha-da-raiz da cana-de-açúcar) (Alves, 1998). De acordo com BuENO (2010), no Brasil, o fungo M. anisopliae vem sendo usado com sucesso para o controle das cigarrinhas das pastagens e de cana-de-açúcar.

As estruturas mais produzidas e comercializadas de M. anisopliae são os conídios, produzidos na superfície de meio de cultura sólido, dentro de diferentes recipientes conforme o objetivo e escala de produção (Almeida; BATISTA Filho, 2006), sendo o arroz o substrato mais utilizado para a produção conidial. Isto se deve, provavelmente, à combinação de fatores como balanço nutricional, custo, ampla disponibilidade mundial, características físicas como tamanho eforma do grão, propriedades dehidratação e integridade estrutural mesmo após a colonização pelo fungo (JenKINs et al., 1998).

A produção de fungos entomopatogênicos representa uma etapa crítica e limitante no desenvolvimento de um programa de controle microbiano para uma determinada praga. A pesquisa de novas metodologias de sistemas de produção é muito importante para tornar o controle microbiano de pragas economicamente viável para ser aplicado em grandes áreas (TANZINI, 2002).

Segundo OtTATI-DE-Lima (2007), devidoaoelevado preço que o arroz vem alcançando no comércio, o custeio do substrato para o fungo tem acarretado despesas crescentes aos fabricantes. Estudos têm sido realizados desde a década de 80 com o objetivo de avaliar substratos alternativos e mais baratos, incluindo resíduos agroindustriais (CRUZ et al., 1983; Alvarenga etal.,1988; MagalHães; FrazÃo, 1996; VIlas BoAset al., 1996; Alveset al., 1997a; Alveset al., 1997b; DALlaSANTAetal.,2005), havendo uma tendência para a regionalização da produção (Alves et al., 1997b). Tal tendência se intensificou nos últimos anos com o apoio do Instituto Biológico, o qual vem prestando consultoria na instalação de biofábricas do fungo $M$. anisopliae para o controle biológico da cigarrinha da cana-de-açúcar (Leite et al., 2003).

Oresíduo úmido da produção de cerveja, também denominado farelo ou bagaço de cevada, pode ser descrito como uma massa resultante da aglutinação da casca com resíduos do processo de mosturação. Segundo CABRAL FilHo (1999), os altos valores de proteína e açúcares resultantes das reações de hidrólise do conteúdo amiláceo do cereal são os maiores atrativos neste resíduo, embora ocorra variação na sua composição bromatológica em função do processo industrial no qual foi gerado.

Oresíduo úmido de fecularia ou farelo ou bagaço de mandioca é gerado durante o processo de extração da fécula de mandioca e, após seco, possui um teor de amido de aproximadamente $64 \%$ e $61 \%$, respectivamente, para os processos de extração manual e mecânico (RocHA, 2005).

$\mathrm{O}$ arroz vermelho, de menor valor comercial que o arroz branco, é um biótipo pertencente à mesma espécie do arroz comum (Oryza sativa L.), entretanto, é considerado uma planta invasora, pois infesta as lavouras e compete com o arroz branco, limitando o seu potencial de produtividade (AgostinetTo et al., 2001).

Neste contexto, o presente trabalho visou determinar o potencial de utilização de resíduos agroindustriais e do arroz vermelho, disponíveis na região oeste do Estado do Paraná, na composição de meios de cultura sólidos para a produção de conídios de M. anisopliae.

\section{MATERIAL E MÉTODOS}

\section{Micro-organismo e preparo do inóculo}

Osexperimentosforam conduzidos no Laboratório de Tecnologia das Fermentações da UNIOESTE, Campus de Cascavel, PR. Empregou-se o fungo M. anisopliae (isolado E9), armazenado na forma de conídios puros, em frascos Eppendorf a $-4^{\circ} \mathrm{C}$. Para a produção inicial de conídios utilizaram-se placas de Petri contendo meio para conidiogênese (MC) composto de (g/1.000 mL deágua destilada): $1,58 \mathrm{NaNO}_{3}$; 
$0,36 \mathrm{KH}_{2} \mathrm{PO}_{4} ; 0,60 \mathrm{MgSO}_{4} .7 \mathrm{H}_{2} \mathrm{O} ; 1,05 \mathrm{NaHPO}_{4} .7 \mathrm{H}_{2} \mathrm{O}$; $1,00 \mathrm{KCl} ; 5,0$ extrato de levedura; 10,0 glicose; 20,0 ágar (Alves, 1998). A inoculação dos conídios nas placas foi realizada em câmara de fluxo laminar vertical. Em seguida, as placas foram incubadas a 25 $\pm 1^{\circ} \mathrm{C}$ e fotofase de 12 horas, por um período de 7 a 10 dias para crescimento e conidiogênese do fungo. Após este período, os conídios foram coletados, raspando a superfície dos meios de cultura nas placas e transferidos para tubos de vidro fechados com filme PVC e armazenados sob refrigeração a $4^{\circ} \mathrm{C}$ por um período não superior a 10 dias. Para o preparo das suspensões, os conídios foram adicionados em água estéril + espalhante adesivo (Tween $80 ®$ ) a 0,01\%.Em seguida, foi estimada a concentração dos conídios em câmara de Neubauer e as suspensões foram padronizadas em $1 \times 10^{8}$ conídios $/ \mathrm{mL}$.

Teste preliminar para ajuste da umidade dos meios para $70 \pm 10 \%$

O teste consistiu na adição de diferentes volumes deágua destilada em $30 \mathrm{~g}$ de cada substrato, contidos em frascos Erlenmeyer de vidro $(250 \mathrm{~mL})$. Os frascos foram autoclavadose, após resfriamento, realizou-se a pesagem. Em seguida, os frascos foram levados à estufa $\left(80^{\circ} \mathrm{C}\right)$ para secagem dos materiais até peso constante. Realizou-se nova pesagem e, após a subtração da massa seca, foram calculados os volumes de água a serem adicionados a cada substrato de forma a resultar numa umidade em torno de $70 \pm 10 \%$ após a autoclavagem, conforme descrito na Tabela 1.

Avaliação da produção de Metarhizium anisopliae em meio sólido à base de resíduos agroindustriais

Foram avaliados substratos ricos em carboidratos como arroz polido (meio padrão), arroz vermelho, arroz polido suplementado com melaço (resíduo da produção de açúcar) a 2,5\%,5\% e 10\%, resíduo da cervejaria, resíduo da fecularia, arroz polido e resíduo de cervejaria (1:1) e arroz polido e resíduo de fecularia (1:1).

Tabela 1 - Volumes de água destilada e de solução de melaço (em diferentes concentrações) necessários para se obter $70 \pm 10 \%$ de umidade em 30 g de substrato.

\begin{tabular}{lc}
\hline Substrato (30 g) & Volume (mL) \\
\hline Arroz & 60 \\
Arroz vermelho & 60 \\
Arroz + melaço (2,5\%) & 60 \\
Arroz + melaço (5\%) & 60 \\
Arroz + melaço (10\%) & 60 \\
Res. fecularia & 10 \\
Arroz + resíduo de fecularia (1:1) & 40 \\
Res. cervejaria & 0 \\
Arroz + resíduo decervejaria (1:1) & 30 \\
\hline
\end{tabular}

O experimento foi realizado em frascos Erlernmeyer de $250 \mathrm{~mL}$, contendo $30 \mathrm{~g}$ do substrato com teor de umidade de $70 \pm 10 \%$, sendo preparados 3 frascos para cada meio de cultura. Para avaliação das misturas de substratos, foram utilizados $15 \mathrm{~g}$ de cada. Os frascos foram autoclavados a $1 \mathrm{~atm}$, $121^{\circ} \mathrm{C}$ por 20 minutos e resfriados. Em seguida, em câmara de fluxo laminar vertical e com o auxílio de um bastão de vidro estéril, fez-se a desagregação dos meios sólidos para permitir que o fungo se desenvolvesse uniformemente sobre todo o substrato. Após inoculação de $0,5 \mathrm{~mL}$ da suspensão de conídios $\left(1 \times 10^{8}\right.$ conídios $\left./ \mathrm{mL}\right)$, os frascos foram fechados com tampão de algodão e gaze e incubados $25 \pm 1^{\circ} \mathrm{C}$ e fotofase de 12 horas durante 7 dias. Para a avaliação da perda de umidade, foram incubados frascos não inoculados, contendo o substrato e $0,5 \mathrm{~mL}$ de água + espalhante adesivo (Tween 80 ) a $0,01 \%$, os quais foram pesados antes e após o período de incubação e após secagem em estufa a $80^{\circ} \mathrm{C}$ até peso constante.

Após o período de incubação, cada fraco recebeu $120 \mathrm{~mL}$ de água destilada mais espalhante adesivo (Tween 80 ) a $0,01 \%$ e foi submetido à agitação com bastão de vidro estéril até a visualização do desprendimento total dos conídios da matriz sólida por, pelo menos, cinco minutos. Desta suspensão, coletou-se uma alíquota de $0,1 \mathrm{~mL}$ a qual foi adicionada a 0,9 mL deágua + espalhanteadesivo (Tween 80 ) a $0,01 \%$, obtendo-se uma diluição 1:10 para realização da contagem em câmara de Neubauer sob microscópio de luz (aumento de 400×).

\section{Teste de viabilidade dos conídios}

Amostras dos conídios produzidos nos diferentes meios foram tomadas e submetidas a diluições seriadas, até se obter uma concentração de $1 \times 10^{6}$ conídios/mL. Desta suspensão, inoculou-se, em triplicata, $100 \mu \mathrm{L}$ em placas de Petri contendo meio BDA (Batata-Ágar-Dextrose), que em seguida foram incubadas por 18 horas a $25 \pm 1^{\circ} \mathrm{C}$ e fotofase de 12 horas. Após esse período, foram realizadas as contagens em cada placa, de 200 a 300 conídios viáveis ou não, sob microscópio de luz (aumento de 400×).

\section{Avaliação da atividade inseticida}

Os meios selecionados nas etapas anteriores foram novamente empregados para a produção de conídios, seguindo os mesmos procedimentos. Após a produção, os frascos contendo meio de cultura e conídios foram armazenados em freezer $\left(4^{\circ} \mathrm{C}\right)$ até a disponibilização de insetos para os bioensaios. Para tal,foram utilizadas lagartas de Spodoptera frugiperda, obtidas a partir de criação de insetos no próprio laboratório, mantidas em copos plásticos de $50 \mathrm{~mL}$ com tampa e contendo dieta artificial (PARRA, 1996) 
desde a eclosão dos ovos, à temperatura ambiente. As lagartas encontravam-se no terceiro ínstar, com aproximadamente $1 \mathrm{~cm}$ de comprimento e foram divididas em três repetições de 15 indivíduos para cada tratamento. Os insetos foram imersos por 10 segundos na suspensão de conídios contendo $1 \times 10^{9}$ conídios/mLemágua destilada + espalhanteadesivo (Tween 80) a 0,01\%. Na testemunha, as lagartas foram imersas apenas emágua destilada estéril + espalhante adesivo (Tween 80 ) a $0,01 \%$. Após a inoculação, as lagartas foram acondicionadas individualmente em placas de Petri contendo a dieta artificial e foram mantidas a $25 \pm 1^{\circ} \mathrm{C}$ e fotofase de 12 horas.

Osinsetos foram observados diariamente durante 10 dias, sendo que os mortos foram retirados, imersos em solução de álcool $70 \%$ por 10 segundos e depois em água destilada e mantidos em câmara úmida para confirmação da mortalidade pelo fungo. Para tal, as lagartas foram colocadas individualmente em placas de Petri contendo papel-filtro umedecido e mantidas em potes plásticos fechados com tampa e com fundo recoberto por espuma de poliuretano umedecida até a saturação. Assim, foram incubados nas mesmas condições descritas anteriormente, por mais 10 dias.

\section{Estimativa dos custos de produção}

A análise de custos foi realizada apenas com base no preço da matéria-prima para composição do meio, obtido em supermercados e também junto aos fornecedores do resíduo de cervejaria e de fecularia. Nãoforam considerados gastos com transporte e demais custos do processo de produção (investimento e depreciação de equipamentos consumo de energia, mão-de-obra etc).

\section{Análise estatística}

Os experimentos foram realizados segundo o delineamento experimental inteiramente aleatorizado, sendo os dados obtidos analisados estatisticamente quanto à variância (teste F) e as médias comparadas entre si (teste Tukey), ambos no nível de $5 \%$ de probabilidade, utilizando-se o programa computacional Sisvar (FERREIRA, 2003).

\section{RESULTADOS E DISCUSSÃO}

\section{Avaliação da produção de Metarhizium anisopliae em meio sólido à base de resíduos agroindustriais}

Entre os diferentes meios testados, os que proporcionaram maior produção de conídios foram o meio composto por arroz + resíduo da cervejaria (1:1), obtendo-se 11,3 × $10^{8}$ conídios/g de substrato, e o arroz polido $\left(9,6 \times 10^{8}\right.$ conídios/g) (Tabela 2). A elevada produção de conídios verificada na mistura arroz + resíduo da cervejaria pode ser atribuída ao suporte de celulose (casca da cevada), semelhante ao verificado por DALLA SANTA et al. (2005), em estudos utilizando batata e bagaço de cana de açúcar para a produção de conídios de Beauveria bassiana e também por MAGALHÃES; FRAZÃO (1996), que verificaram que a palha de arroz + farelo de arroz e o arroz parboilizado foram os melhores substratos para a produção de $M$. flavoviride.Segundo LoNSANE et al. (1985), a utilização de um substrato fibroso favorece a aeração, causa menores problemas de compactação e maior superfície de crescimento durante um cultivo em substrato sólido.

O resíduo da cervejaria empregado isoladamente, no entanto, proporcionou uma conidiogênese média de apenas $1,9 \times 10^{8}$ conídios/g (Tabela 2), provavelmente por razões nutricionais, não tendo exercido o duplo papel de suporte e substrato, como se esperava. Neste meio, o teor de umidade foi o maior verificado (aproximadamente 77\%), porém, a perda de umidade aolongo docultivo foi tambémelevada $(7,63 \%$ ) (Tabela 3), não sendo possível afirmar se este foi outro fator que contribuiu para a baixa produção de conídios. $\mathrm{O}$ teor ótimo de umidade para o crescimento de fungos e produçãodeconídios precisa seridentificado paracada combinação de substrato/isolado, pois o conteúdo de umidade tem um papel essencial na produção de conídios, embora a otimização deste parâmetro possa ser complexa (JENKINs et al., 1998). Segundo PANDEY (2003), alta umidade resulta numa diminuição da porosidade do substrato, a qual impede a penetração do oxigênio, enquanto que um baixo conteúdo de umidade pode levar a uma pobre disponibilidade dos nutrientes, comprometendo o crescimento microbiano.

Tabela 2-Quantidades médias de conídios de M. anisopliae obtidas em diferentes substratos após incubação por 7 dias ( $25^{\circ} \mathrm{C}$ e fotofase de $\left.12 \mathrm{~h}\right)$

\begin{tabular}{|c|c|}
\hline Substrato & $\begin{array}{c}\text { Concentração } \\
\left(\times 10^{8} \text { conídios } / g\right)^{*}\end{array}$ \\
\hline Arroz & $9,59 \mathrm{a}$ \\
\hline Arroz vermelho & $6,92 \mathrm{~b}$ \\
\hline Arroz + melaço(2,5\%) & $4,63 \mathrm{c}$ \\
\hline Arroz + melaço(5\%) & $5,09 \mathrm{~b} \mathrm{c}$ \\
\hline Arroz + melaço(10\%) & $4,19 \mathrm{c}$ \\
\hline Res. fecularia & $0,20 \mathrm{~d}$ \\
\hline Arroz + resíduo de fecularia $(1: 1)$ & $4,14 \mathrm{c}$ \\
\hline Resíduo cervejaria & $1,91 \mathrm{~d}$ \\
\hline Arroz + resíduo de cervejaria $(1: 1)$ & $11,30 \mathrm{a}$ \\
\hline $\mathrm{CV}(\%)$ & 13,27 \\
\hline
\end{tabular}


A produção de conídios de M. anisopliae no arroz vermelho foi inferior à produção no arroz branco, usualmente empregado na produção de conídios deste fungo. Constatou-se que, após cozimento em autoclave, o arroz vermelho apresentou maior agregação entre os grãos que o arroz branco, com consequente redução de sua área superficial, além de uma maior dificuldade para desprendimento dos conídios da matriz sólida.

A proporção carbono e nitrogênio (C:N) do meio é um importante fator a ser considerado no desenvolvimento de meios decultura, pois sua composição pode ter uma estreita relação com o custo e a qualidade do fungo produzido, podendo influenciar no tipo, formato e quantidade de propágulo, sendo que meios ricos em $\mathrm{C}$, mas deficientes em $\mathrm{N}$, tendem a produzir maior quantidade de conídios (LeITE et al., 2003). O melaço possui cerca de $50 \%$ de açúcares e 3\% de matérias nitrogenadas (Lima et al., 2001), o que poderia contribuir para o favorecimento da conidiogênese. No entanto, a suplementação do arroz branco com solução de melaço a 2,5\%, 5\% e 10\% não favoreceu a produção de conídios em relação ao meio padrão, ou seja, o arroz branco.

Embora os farelos de fecularia apresentem em sua composição média $75 \%$ amido, $15 \%$ de fibras, 1,6\% de cinzas, $2 \%$ de proteínas, $1 \%$ de açúcares e $0,8 \%$ de matéria graxa, expressos na base seca (CEREDA, 1996), dentre todos meios estudados neste trabalho, o resíduo da fecularia foi o substrato que proporcionou ao fungo a menor taxa de conidiogênese. Este meio apresentou uma perda de umidade de 4,86\% durante os 7 dias de incubação (Tabela 2), mas per- manecendo ainda, no final do período, com umidade de $68 \%$, indicando que a baixa produção de conídios neste meio pode não estar associada diretamente ao seu conteúdo de umidade, mas provavelmente, ao problema de compactação observado.

Com base nos resultados obtidos e considerando que a contagem de conídios não deve ser usada como parâmetro único da adequabilidade de um meio, o meio de arroz + resíduo de cervejaria (1:1) foi selecionado para novos testes, tomando-se como comparação o arroz, meio padrão para cultivo de M. anisopliae. Segundo JACKSON (1997), após a etapa de seleção de um meio que proporcione uma boa produção da forma desejada do fungo, é importante avaliar sua capacidade de suportar processos de secagem, sua estabilidade e sua virulência.

\section{Teste de viabilidade dos conídios}

Não foi verificada diferença estatística entre a porcentagem de germinação (18 horas de incubação) de conídios de M. anisopliae produzidos no arroz e na mistura de arroz + resíduo de cervejaria, as quais apresentaram-se em torno de $85 \%$ (Tabela 4 ). No entanto, os valores encontrados foram ligeiramente inferiores aos verificados por VILAs BoAs et al. (1996) ao avaliarem o cultivo de $M$. anisopliae em arroz e meios alternativos tais como fava, feijão, sorgo e caupi. Vale ressaltar que diferindo do autor citado, neste trabalho, os conídios foram armazenados por 60 dias, em condições ideais para a preservação de fungos $\left(-4^{\circ} \mathrm{C}\right)$, porém na ausência de agentes crioprotetores.

Tabela 3 - Variação da umidade dos substratos empregados para o cultivo de M. anisopliae após incubação por 7 dias $\left(25^{\circ} \mathrm{C}\right.$ e fotofase de $\left.12 \mathrm{~h}\right)$

\begin{tabular}{lcc}
\hline Substrato & $\begin{array}{c}\text { Umidade } \\
\text { inicial (\%) }\end{array}$ & $\begin{array}{c}\text { Umidade } \\
\text { final (\%) }\end{array}$ \\
\hline Arroz & 69,50 & 66,41 \\
Arroz vermelho & 66,78 & 64,03 \\
Arroz + melaço(2,5\%) & 67,77 & 66,17 \\
Arroz + melaço (5\%) & 67,24 & 62,58 \\
Arroz + melaço(10\%) & 64,49 & 62,61 \\
Res. fecularia & 72,89 & 68,03 \\
Arroz + resíduo de fecularia(1:1) & 72,83 & 69,99 \\
Resíduo de cervejaria & 76,91 & 69,28 \\
Arroz + resíduo de cervejaria (1:1) & 71,26 & 67,72 \\
\hline CV $\%$ ) & 5,52 & 4,13 \\
\hline
\end{tabular}

Tabela 4 - Comportamento de M. anisopliae produzido em diferentes substratos quanto à viabilidade de conídios e à mortalidade de larvas de $S$. frugiperda

\begin{tabular}{lcc}
\hline Substrato & Viabilidade média (\%) & Mortalidade confirmada (\%) \\
\hline Arroz puro & $84,46 \mathrm{a}$ & $13,33 \mathrm{a}$ \\
Arroz + resíduo de cervejaria (1:1) & $85,55 \mathrm{a}$ & $24,44 \mathrm{a}$ \\
Testemunha & - & $2,22 \mathrm{a}$ \\
\hline $\mathrm{CV}(\%)$ & 0,83 & 71,1 \\
\hline
\end{tabular}

*Valores seguidos por letras iguais nas colunas não diferem entre si ao nível de $5 \%$ de probabilidade pelo Teste de Tukey. 
Segundo Hong et al. (1997), Alves et al. (1996 e Alves et al. (2002), a temperatura de estocagem, o conteúdo de umidade e o tipo de formulação são os principais fatores que influenciam na longevidade dos conídios. Em estudo realizado com B. bassiana, conídios armazenados em congelador e freezer mantiveram $100 \%$ da viabilidade após um período de armazenamento de 7 anos, no entanto, estes autores observaram que $100 \%$ da germinação somente ocorreu após 36-72 horas, enquanto que os conídios recém-produzidos germinaram em apenas 12 horas (Alves et al., 1996). No presente estudo, o reduzido tempo de incubação utilizado para o fungo armazenado pode ter sido o motivo para o resultado obtido.

\section{Avaliação da atividade inseticida}

Observou-se que a atividade inseticida dos conídios produzidos no meio formulado com arroz + resíduo de cervejaria frente a $S$. frugiperda não diferiu estatisticamente dos valores verificados para os conídios produzidos no arroz, na concentração empregada neste estudo ( $10^{9}$ conídios $\left./ \mathrm{mL}\right)$, sendo, para ambos os meios testados, inferior a 25\% (Tabela 4). Dados da literatura têm demonstrado uma baixa susceptibilidade de $S$. frugiperda ao fungo $M$. anisopliae. Segundo Rodrigues; PRATISSOLI (1989), M. anisopliae não mostrou nenhum efeito letal nas três concentrações testadas $\left(10^{3}, 10^{5}\right.$ e $\left.10^{7}\right)$, enquanto que LECUONA; Díaz (2001) verificaram que 6 das 15 cepas estudadas não foram patogênicas e que somente 3 cepas superaram $80 \%$ de mortalidade.

A atividade inseticida dos fungos entomopatogênicos está relacionada à produção de proteases degradadoras de cutícula. No caso de M. anisopliae, proteases do tipo Pr1 e Pr2 foram identificadas e caracterizadas, sendo a presença de suas isoformas influenciada pelo meio, ou seja, a expressão dos genes pr1 e pr2 depende do nível das fontes de carbono e nitrogênio e da presença de proteínas indutoras no meio (St. Leger et al., 1988; St. LegER et al., 1994; SHAH et al., 2005). A depleção de reservas endógenas e níveis de nutrientes insuficientes para promover a repressão catabólica de proteases favorecem o processo de infecção do hospedeiro (St. LEGER et al., 1988). Segundo Alves et al. (1996), fatores bióticos e abióticos estão envolvidos na perda da atividade inseticida de vários agentes de controle microbiano, podendo haver uma correlação entre taxa ou tempo de germinação e virulência, dependendo do inseto alvo. Comojá mencionado anteriormente, não houve diferença na porcentagem de germinação de conídios de $M$. anisopliae produzidos em ambos os meios, o que viria a explicar, juntamente com fatores nutricionais, os resultados obtidos para a mortalidade de $S$. frugiperda.

\section{Estimativa do custo de produção}

Considerando-se apenas o custo do meio de cultura e a produção final obtida tanto no arroz puro quanto no arroz + resíduo de cervejaria, as quais foram as melhores e não diferiram significativamente entre si, verificou-se redução de aproximadamente $50 \%$ no custo de produção de conídios no meio constituído de arroz + resíduo de cervejaria em relação à produção no arroz, já que o resíduo é vendido por, aproximadamente, $\mathrm{R} \$ 30,00 / \mathrm{t}$, ou seja, $\mathrm{R} \$ 0,03 / \mathrm{kg}$, enquanto que o preço médio do arroz é $\mathrm{R} \$ 2,00 / \mathrm{kg}$. Além disto, o resíduo de cervejaria é empregado in natura, sem necessidade de cozimento, o que pode vir a reduzir ainda mais os custos e a mão-de-obra durante o preparo.

\section{CONCLUSÕES}

$\mathrm{O}$ arroz + resíduo úmido de cervejaria poderá representar um meio de cultura alternativo para a produção de conídios de M. anisopliae, visto queneste meio, o fungo manteve elevada conidiogênese, sem perda da atividade inseticida. No entanto, fazem-se necessários estudos com outros isolados do fungo e bioensaios com outros insetos.

Ressalta-se que este meio poderá ser utilizado em grande escala, levando-se em consideração as importantes reduções no custo de produção e sua disponibilidade na região Oeste do Paraná em todas as épocas do ano.

\section{AGRADECIMENTOS}

Os autores agradecem à FINEP pelo financiamento deste trabalho, parte integrante do Projeto BIOAGROPAR, e à Fundação Araucária e ao CNPq pela concessão das bolsas de iniciação científica e produtividade aos autores.

\section{REFERÊNCIAS}

AGOSTINETTO, D.; FLECK, N.G.; RIZZARDI, M.A.; MEROTTO JUNIOR, A.; VIDAL, R.A. Arroz vermelho: ecofisiologia e estratégias de controle. Ciência Rural, v.31, n.2, p.341-349, 2001.

ALMEIDA, J.E.M; BATISTA FILHO, A. Controle biológico da cigarrinha-da-raiz da cana-de-açúcar com o fungo Metarhizium anisopliae. Boletim Técnico do Instituto Biológico. São Paulo, n.16, p.1-19, 2006.

ALVARENGA, A.R.M.; CRUZ, B.P.B.; OLIVEIRA, D.A.; SILVEIRA, A.P.; BULISANI, E.A. Novos testes de cul- 
tivo de fungos utilizados em controle biológico usando meios de cultura naturais líquidos. Arquivos do Instituto Biológico, São Paulo, v.55, n.1/4, p.31-35, 1988.

ALVES, S.B.; PEREIRA, R.M.; STIMAC, J.L.; VIEIRA, S.A. Delayed germination of Beauveria bassiana conidia after prolonged storage at low, above-freezing temperatures. Biocontrol Science and Technology, v.6, 575-581, 1996.

ALVES, L.F.A.; ALVES, S.B.; PEREIRA, R.M.; CAPALBO, D.M.F. Production of Bacillus thuringiensis Berliner var. kurstaki grown in alternative media. Biocontrol Science and Technology, v.7, 377-83, 1997a.

ALVES, L.F.A.; ALVES, S.B.; CAPALBO, D.M.F. Seleção de matéria-prima para a elaboração de meio de cultura para a produção de Bacillus thuringiensis var. kurstaki Berliner. Anais da Sociedade Entomológica do Brasil, v.26, n.2, 379-382, $1997 \mathrm{~b}$.

ALVES. S.B. (Ed.). Controle Microbiano de Insetos. 2.ed. Piracicaba: FEALC, 1998. 1163p.

ALVES, R.T.; BATEMAN, R.P.; GUNN, J.; PRIOR, C.; LEATHER, S.R. Effects of different formulations on viability and medium-term storage of Metarhizium anisopliae conidia. Neotropical Entomology, v.31, n.1, p.9199, 2002.

BUENO, V.P. Controle biológico na região sudeste. Revista G.Bio, v.1, p.4-6, 2010.

CABRAL FILHO, S.L.S. Avaliação do resíduo de cervejaria em dietas de ruminantes através de técnicas nucleares e correlatas. 1999. 68f. Dissertação (Mestrado em Ciências Área de Tecnologia Nuclear na Agricultura) - Centro de Energia Nuclear na Agricultura, Universidade de São Paulo, Piracicaba, 1999.

CEREDA, M.P. (Ed.). Caracterização, usos e tratamentos de resíduos da industrialização da mandioca. Botucatu: Centro de Raízes Tropicais, Universidade Estadual Paulista, 1996. 56p.

CRUZ, B.P.B; ABREU, O.C.; OLIVEIRA, D.A.; CHIBA, S. Crescimento de Metarhizium anisopliae (Metsch.) Sorokin em meios de cultura naturais, líquidos. Biológico, São Paulo, v.49, p.111-116, 1983.

DALLA SANTA, H.S.; DALLA SANTA, O.R.; BRAND, D.; VANDENBERGHE, L.P.S.; SOCCOL, C.R. Spore production of Beauveria bassiana from agro-industrial residues. Brazilian Archieves of Biology and Technology, v.48, 51-60, 2005.

FERREIRA, D.F. (Ed.). Sisvar: versão 4.3. Lavras: DEX/ UFLA, 2003.

HONG, T.D., R.H. ELLIS; D. MOORE. Development of a model to predict the effect of temperature and moisture on fungal spore longevity. Annals of Botany, v.79, p.121-128, 1997.
JACKSON, M.A. Optimizing nutritional conditions for the liquid culture production of effective fungal biological control agents. Journal of Industrial Microbiology $\mathcal{E}$ Biotechnology, v.19, n.3, p.180-187, 1997.

JENKINS, N.E.; HEVIOFO, G.; LANGEWALD, J.; CHERRY, A.J.; LOMER, C.J. Development of mass production technology for aerial conidia for use as mycopesticides. Biocontrol News and Information, v.31, n.2, p.21-31, 1998.

KASSA, A. Development and testing of mycoinsecticides based on submerged spores and aerial conidia of the entomopathogenic fungi Beauveia bassiana and Metarhizium anisopliae (Deuteromycotina: Hyphomycetes) for control of locusts, grasshoppers and storage pests. 2003. 27f. Thesis (Doctoral of Agricultural Sciences) - Faculty of Agricultural Sciences, George-August, University Göttingen. Göttingen, 2003.

LECUONA, R.E.; DÍAZ, B. M. Susceptibilidad de Spodoptera frugiperda (J. E. Smith) a los hongosentomopatógenos Nomuraea rileyi, Metarhizium anisopliae y Beauveria bassiana. Revista de Investigaciones Agropecuarias, v.30, n.1, p.25-42, 2001.

LEITE, L.G.; BATISTA FILHO, A.; ALMEIDA, J.E.M; ALVES, S.B. (Ed.). Produção de fungos entomopatogênicos. Ribeirão Preto: A.S. Pinto, 2003. 92p.

LIMA, U.A.; AQUARONE, E.; BORZANI, W.; SCHMIDELL, W. Biotecnologia industrial - processos fermentativos e enzimáticos. São Paulo: Edgard Blücher, 2001. v.3, $593 \mathrm{p}$.

LONSANE, B.K.; GHILDYAL, N.P.; BUDIATMAN, S.; RAMAKRISHNA, S.V. Engineering aspects of solidstate fermentation. Enzyme and Microbial Technology, v.7, n.6, p.258-265, 1985.

MAGALHÃES, B.P.; FRAZÃO, H.S. Effects of temperature, water content and substrate on conidial production of Metharhizium flavoviride. Revista de Microbiologia, v.27, p.242246, 1996.

MELO, I. S.; AZEVEDO, J.L. Controle biológico. Jaguariúna: EMBRAPA, 1998. v.1, 264p.

OTTATI-DE-LIMA, E.L. Produção de Metarhizium anisopliae (Metsch.) Sorok e Beauveria bassiana (Bals.) Vuill. em diferentes substratos e efeito da radiação ultravioleta e da temperatura sobre estruturas infectivas desses entopamopatôgenos. 2007. 92f. Tese (Doutorado em Agronomia - Área de Proteção de Plantas) - Faculdade de Ciências Agronômicas UNESP, Botucatu, 2007.

PANDEY, A. Solid-state fermentation. Biochemical Engineering Journal, v.13, n.2/3, p.81-84, 2003.

PARRA, J.R.P. Técnicas de criação de insetos para programas de controle biológico. 3.ed. Piracicaba: FEALQ, 1996. $137 \mathrm{p}$. 
RODRIGUES, C.; PRATISSOLI, D. Avaliação da patogenidade dos fungos entomógenos Beauveria bassiana e Metarhizium anisopliae sobre lagartas de Spodoptera frugiperda. Revista de Cultura UFES, v.14, n.39/40, p.8589, 1989.

ROCHA, A.S. Caracterização e aproveitamento do farelo residual no processamento de fécula de mandioca na elaboração de biscoitos. 2005. 48f. Dissertação (Mestrado em Ciências Agrárias - Área de Fitotecnia) - Universidade Federal da Bahia, Cruz das Almas, 2005.

SHAH, F.A.; CHENG, S.W.; BUTT, T.M. Nutrition influences growth and virulence of the insect-pathogenic fungus Metarhizium anisopliae. FEMS Microbiology Letters, v.251, p.259-266, 2005.

\section{St. LEGER, R.J.; DURRANDS, P.K.; COOPER, R.M.;}

CHARNLEY, A.K. Regulation of production of proteolitic enzymes by entomopathogenic fungus Metarhizium anisopliae. Archives of Microbiology, v.150, p.413-416, 1988.
St. LEGER, R.J.; BIDOCHKA, M.J.; ROBERTS, D.W. Isoforms of the cuticle-degrading Pr1 proteinase and production of a metalloproteinase by Metarhizium anisopliae. Archives of Biochemistry and Biophysics, v.313, p.1-7, 1994.

TANZINI, M.R. Controle do percevejo-de-renda-daseringueira (Leptopharsa heveae) com fungos entomopatogênicos. 2002. 140f. Tese (Doutorado em Ciências Área de Entomologia) - Escola Superior de Agricultura Luiz de Queiroz, Universidade de São Paulo, Piracicaba, 2002.

VILAS BOAS, A.M.; ANDRADE, R.M.; OLIVEIRA, J.V. Diversificação de meios de cultura para a produção de fungos entomopatogênicos. Arquivos de Biologia e Tecnologia, v.39, 123-128, 1996.

Recebido em 11/5/09

Aceito em 10/8/10 